\title{
Two new species of Primulina (Gesneriaceae) from limestone karsts of China
}

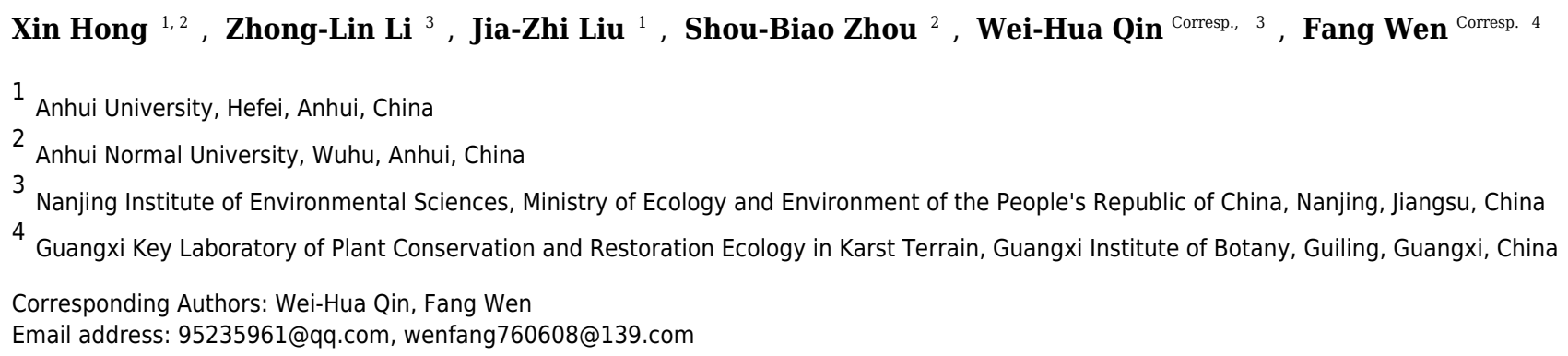

The limestone karst area of South China is a major biodiversity hotspot of global terrestrial biomes. During extensive field work on the Guangxi limestone formations, two unknown species of Gesneriaceae were collected. After conducting a comprehensive study of the literature and herbarium specimens, Primulina davidioides and $P$. hiemalis are recognized as two species new to science, and described and illustrated here. $P$. davidioides is morphologically close to $P$. lunglinensis based on the shape of the leaf and flower, but it can be easily distinguished by the shape of the bracts, corolla and stigma, indumentum of peduncles, pedicels and pistil, number of staminodes. $P$. hiemalis is closely relate to $P$. luzhaiensis in vegetative appearance, but differs in the shape of the calyx and stigma, and number of bracts and staminodes, indumentum of the leaf blade and peduncle, and position of stamens in the corolla tube. Considering that not enough is known about their populations, it is proposed that their conservation statuses should currently be classed as data deficient (DD) according to the IUCN Red List Category and Criteria. 
1 Two new species of Primulina (Gesneriaceae) from limestone karsts of China

2

3 Xin Hong1,3, Zhong-Lin Li², Jia-Zhi Liu', Shou-Biao Zhou ${ }^{3}$, Wei-Hua Qin ${ }^{2}$, Fang Wen ${ }^{4}$

4

$5 \quad{ }^{1}$ Anhui University, Hefei, Anhui, China

$6 \quad{ }^{2}$ Nanjing Institute of Environmental Sciences, Ministry of Ecology and Environment of the

7 People's Republic of China, Nanjing, Jiangsu, China

$8{ }^{3}$ Anhui Normal University, Wuhu, Anhui, China

$9{ }^{4}$ Gesneriad Conservation Centre of China, Guangxi Key Laboratory of Plant Conservation and

10 Restoration Ecology in Karst Terrain, Guangxi Institute of Botany, Guilin, Guangxi Zhuang

11 Autonomous Region, China

12

13 Corresponding author:

14 Wei-Hua Qin ${ }^{2}$

15 Email address: 95235961@qq.com;

16 Fang Wen ${ }^{3}$

17 Email address: wenfang760608@139.com. 


\section{ABSTRACT}

20 The limestone karst area of South China is a major biodiversity hotspot of global terrestrial

21 biomes. During extensive field work on the Guangxi limestone formations, two unknown species

22 of Gesneriaceae were collected. After conducting a comprehensive study of the literature and

23 herbarium specimens, Primulina davidioides and $P$. hiemalis are recognized as two species new

24 to science, and described and illustrated here. $P$. davidioides is morphologically close to $P$.

25 lunglinensis based on the shape of the leaf and flower, but it can be easily distinguished by the

26 shape of the bracts, corolla and stigma, indumentum of peduncles, pedicels and pistil, number of

27 staminodes. P. hiemalis is closely relate to $P$. luzhaiensis in vegetative appearance, but differs in

28 the shape of the calyx and stigma, and number of bracts and staminodes, indumentum of the leaf

29 blade and peduncle, and position of stamens in the corolla tube. Considering that not enough is

30 known about their populations, it is proposed that their conservation statuses should currently be

31 classed as data deficient (DD) according to the IUCN Red List Category and Criteria. 


\section{INTRODUCTION}

34 The tropical and subtropical karst landforms of southern and southwestern China are renowned because of their unrivalled biodiversity and high endemism among the tropical and subtropical floras of the world (Myers et al. 2000; Clements et al. 2006; Hou et al. 2010). Karst areas in

37 South China offer a multitude of ecological niches for plant diversification and speciation (Ai et al., 2015), with about half of all the endemic genera of flowering plants in China (Ying \& Zhang 1994). Among these, the Gesneriaceae form the most abundant with 28 genera amounting to 90\% of all endemic genera of the family in China (Wang et al. 1990, 1998; Li \& Wang 2004;

Möller et al. 2016). At the same time, China is a significant centre of diversity of Old World

42 Gesneriaceae, which consists of 52 genera (Möller et al., 2016), with 75\% of all species endemic

43 to this region (Gao et al., 2015).

44 A great number of new species were described in the genus Primulina (Gesneriaceae) in recent years (Yang et al., 2018), and it is becoming one of the most interesting genera of the Old World Gesneriaceae, comprising more than 170 species (Wang et al. 2011; Möller et al., 2011; Möller et al. 2016). This group shows high levels of endemism and ecological specialisation (Hao et al., 2015), with narrow, island distributions (Wang et al., 1998, Li \& Wang, 2004, Wei et al., 2010), i.e., only in karst towers and caves (Ai et al., 2015). The limestone regions of southern and southwestern China and northern Vietnam possess the highest biodiversity of Primulina with about $80 \%$ of species endemic here (Wei et al. 2010). Many Primulina species pairs can successfully interbreed through artificial experiments (Wen 2008; Zhang et al., 2017), suggesting that Primulina is probably a genus under recent or ongoing speciation and differentiation (Gao et 
54 al., 2015).

55 During our continuous floristic surveys of limestone karsts flora in 2009 and 2010, we

56 have revealed an additional two species of Primulina not previously known. Further fieldwork

57 was conducted at the same locality, and flowering specimens were collected. Available

58 information suggested that these two species are rare and usually occur only at one or two

59 localities. After a comprehensive analysis of the literature (Wang et al. 1990, 1998, Wang \& Li

60 2004, Wei et al. 2010), as well as herbarium specimens of E, GH, HITBC, HN, IBK, IBSC, K,

61 MO, KUN, PE and US (herbarium acronyms according to Index Herbariorum; Thiers 2017), the

specimens were identified as two new taxa of Primulina based on results of detailed examination of morphological anatomical features, which we hereby describe and illustrate.

64

65

66

67

\section{MATERIALS AND METHODS}

\section{Ethics statement}

All the collecting locations of the new species reported in this study are not in any natural conservation area and no specific permissions were required for these locations. Since the species are currently undescribed, inevitably, they are not currently included in the China Species Red List (Wang \& Xie 2004). Our field studies did not involve any endangered or protected species. No specific permits were required for the present study.

\section{Nomenclature}

The electronic version of this article in Portable Document Format (PDF) will represent a published work according to the International Code of Nomenclature for algae, fungi, and plants 
74 (ICN), hence the new names contained in the electronic version are effectively published under

that Code from the electronic edition alone. In addition, new names contained in this work which

have been issued with identifiers by IPNI will eventually be made available to the Global Names

Index. The IPNI can be accessed and the associated information contained in this publication viewed through any standard web browser using the web address "http://ipni.org/". The online version of this work is archived and available from the following digital repositories: PeerJ, PubMed Central, and CLOCKSS.

\section{Material collection}

These two species were collected and examined during the floristic field surveys. In addition, the plants were monitored in the field and nursery in the Gesneriad Conservation

Center of China (GCCC) by the authors over the past eight years. We collected leaf materials of these possible new species, using silica gel to dry them in the field for DNA extraction. We also cultivated about ten young plants from leaf cuttings of each new species for ex situ conservation in the Gesneriad Conservation Center of China (GCCC) so that we can preserve the germ plasma resource of this rare species.

\section{Morphological observations and specimens examined}

An overview of the genus Primulina from southern China and adjacent areas of northern Vietnam was prepared. All available specimens of Primulina stored in the following herbaria were carefully examined: E, GH, HITBC, HN, IBK, IBSC, K, MO, KUN, PE and US. The images of type specimens were also obtained from Tropicos (http://www.tropicos.org) and JSTOR Global Plants (http://plants.jstor.org). Morphological description of the new species was 
based on examination of fresh and pressed specimens. All morphological characters, particularly the details of the flowers, were studied under a stereomicroscope (MD-90, Olympus, Tokyo, Japan), and are described using the terminology presented by Wang et al. (1998). The morphological comparison with other species was based on study of live plants in the field and in cultivation in GCCC, herbarium specimens, and also information gathered in the literature searches.

\section{RESULTS}

Primulina davidioides F. Wen \& Xin Hong sp. nov. (Figs 1, 2)

\section{IPNI:}

Type. China. Guangxi: Donglan County, Donglan Town, Dayou village, growing in rocky crevices and tufa surface on the bottom of a limestone hill, elevation ca. $350 \mathrm{~m}$, 05 May 2012 (fl.), F. Wen \& Xin Hong 201205005 (holotype: IBK; isotype: AHU).

Paratypes. China: Guangxi: Donglan County, Donglan Town, Dawen Village, ca. 350 m, 12 May 2009, F. Wen 0905012 (IBK); ibid., 350 m, 28 May 2011, Xin Hong 201209030 (AHU).

Diagnosis. Primulina davidioides is morphologically close to P. lunglinensis based on elliptical to broadly ovate leaf blade, purple corolla and cylindrical tube, but it can be easily distinguished by puberulent peduncles ( $v s$. glandular puberulent); bracts cordate to suborbicular, base subtruncate, 4-6 6 4-5 cm (vs. elliptic to broadly ovate, base attenuate, $0.6-3.8 \times 0.4-2.7 \mathrm{~cm}$ ); pedicels glandular and eglandular-pubescent ( $v s$. glandular puberulent); corolla ca. $6 \mathrm{~cm}$ long ( $v s$. 3-3.8 cm long), staminodes 3 (vs. 2), pistil ca. $3.7 \mathrm{~cm}$ long, glandular and eglandular pubescent (vs. ca. $2.7 \mathrm{~cm}$ long, puberulent), stigma narrowly obtrapeziform (vs. cuneate) (see Table 1). 
Description. Perennial. Rhizome terete, 2-6 cm long, 1-2 cm in diameter. Leaves in basal

117 rosette, 4-10, opposite; pachyphyllous, rigid and coriaceous when dry, densely pubescent on

118 both surfaces; petiole flattened, 1-2 cm long, 6-10 mm wide, densely pubescent; blade elliptical

119 to broadly ovate, (5-) 11-12.5 cm, 5-10 cm wide, apex somewhat obtuse, base obliquely cuneate,

120 margin shallowly serrate; lateral veins 3-5 on each side, impressed adaxially and prominent

121 abaxially. Cymes 1-3, 5-9 (11)-flowered; peduncles 5-9 (12) $\mathrm{cm}, 4-8 \mathrm{~mm}$ in diameter,

122 pubescent; pedicels ca. $1.4 \mathrm{~cm}$ long, glandular and eglandular-pubescent; bracts 2, opposite, free,

123 cordate to suborbicular, thickly chartaceous, slightly fleshy, leathery when dry, white when

124 flowering, with crinkled and virescent margins, 4-6 cm long, 4-5 cm wide, base subtruncate,

125 apex acute, outside densely puberulent and sparsely strigillose, inner surface glandular-

126 puberulous. Calyx membranous, white to subtranslucent, ca. $7 \mathrm{~mm}, 5$-sect; segments equal,

127 triangular, 2-3 mm wide, margin obscurely serrated from the middle, apex acute, outside densely

128 puberulent. Corolla ca. $6 \mathrm{~cm}$ long, purple, with dark purple lines inside, outside glandular and

129 eglandular-pubescent, inside pubescent near base; tube cylindrical; ca. $4.5 \mathrm{~cm}$ long, ca. $1 \mathrm{~cm}$

130 diameter at mouth, ca. $0.5 \mathrm{~cm}$ in diameter at base; limb distinctly 2-lipped, adaxial lip 2-parted to

the base, lobes ovate, ca. $6 \times 5 \mathrm{~mm}$, 3-lobed from near the middle, lobes oblong, 10-15 × 4-6

mm. Stamens 2, abaxial, adnate to ca. $1.7 \mathrm{~cm}$ above corolla base; filaments white, ca. $1.1 \mathrm{~cm}$,

strongly geniculate near the base, ca. $1 \mathrm{~mm}$ wide, sparsely glandular-puberulous; anthers fused

along their entire adaxial surfaces, reniform-oblong, ca. $3 \mathrm{~mm}$ long, ca. $2 \mathrm{~mm}$ wide, pale yellow,

bearded on the back. Staminodes 3, adaxial, linear, apex capitellate, lateral ones ca. $7 \mathrm{~mm}$ long,

adnate to ca. $1.5 \mathrm{~cm}$ above corolla base, central one ca. $4.5 \mathrm{~mm}$ long, adnate to ca. $0.9 \mathrm{~cm}$ above 
137 corolla base, sparsely glandular-puberulous. Disc ring-shaped, indistinctly lobed, $0.5-0.8 \mathrm{~mm}$

138 high, glabrous. Pistil linear, ca. $3.7 \mathrm{~cm}$ long, green, densely puberulent with both glandular and 139 eglandular hairs; ovary ca. $2.0 \mathrm{~cm}$ long, ca. $1.5 \mathrm{~mm}$ wide. Lower lip of stigma narrowly 140 obtrapeziform, apex retuse, translucent to green, ca. $3 \mathrm{~mm}$ long, recurved. Capsule ca. $5 \mathrm{~cm}$ long, 141 brownish.

142 Distribution, Habitat and Ecology. Primulina davidioides is rare, only found in the type 143 locality, i.e. an unnamed limestone hill ca. $20 \mathrm{~km}$ west of Donglan Town, Donglan County, in 144 northern Guangxi province of southern China. It grows in rocky crevices and tufa surface on the 145 bottom of a limestone hill at an elevation of $350 \mathrm{~m}$ a.s.l. The average temperature of Donglan 146 County is $18.7^{\circ} \mathrm{C}$, the average annual precipitation has been calculated at ca. $1660 \mathrm{~mm}$. The 147 forest where $P$. davidioides occurs is subtropical evergreen broad-leaf forest. Flowering in May, 148 fruiting in September.

149 Etymology. The specific epithet is derived from its cordate to suborbicular bracts with 150 subtruncate base. The shape of the bracts looks similar to the bracts of Davidia involucrate Baill., 151 native to China.

Primulina hiemalis Xin Hong \& F. Wen sp. nov. (Figs 3, 4)

Type: China, Guangxi, Yongfu county, Baishou Town, Chuanyan village, on the moist rock face 155 at the entrance of limestone caves, $526 \mathrm{~m}$ a.s.1., 09 December 2010, F. Wen \& L.F. Fu WFBCJT101209-01 (holotype: IBK; isotype: AHU).

Additional collections. China, Guangxi, Yongfu county, Baishou Town, Baishouyan, on the 
158 moist rock face at the bottom of limestone hills, $511 \mathrm{~m}$ a.s.1., 15 December 2011, F. Wen

159

160

161

162

163

164

165

166

167

168

169

170

171

172

173

174

175

176

177

178

WFBCJT111215-01 (IBK)

Diagnosis. Morphologically, Primulina hiemalis resembles $P$. luzhaiensis since both species

having thick chartaceous leaves, obliquely ovate or oblong leaf blade, purple corolla, 4-6 cm, tubular tube. But it can be readily distinguished from $P$. luzhaiensis by the indumentum of the leaf blade and peduncle (puberulent vs. villous); bracts 3 (vs. 2), lateral ones ca. $2 \mathrm{~cm}$ long (vs. 0.2-0.8 mm long); longer calyx, ca. $1.5 \mathrm{~cm}$ long (vs. $0.5-1 \mathrm{~cm}$ long); stamens adnate to ca. $2 \mathrm{~cm}$ (vs. 1.4-1.7 mm) above the corolla tube base; staminodes 2 (vs. 3), stigma ligulate, apex 2-lobed to middle (vs. obtrapeziform, apex retuse) (shown in Table 2).

Description. Perennial. Rhizome subterete, ca. $1.0-2.5 \times 0.5-2.0 \mathrm{~cm}$ wide, internodes inconspicuous. Leaves in basal rosette, 6-8, opposite; petiole 0.5-3.5 × 0.4-0.6 cm; leaf blade thickly chartaceous, markedly obliquely ovate or oblong, $5.5-9.5 \times 3.5-5.0 \mathrm{~cm}$, apex obtuse, base obviously oblique, cuneate-attenuate, margin crenate, obviously serrated from the base; densely puberulent on both surfaces, lateral veins 4-5 on wider side of midrib, lateral veins inconspicuous, 3-4 on narrower side of midrib. Cymes 2-4, 1-3-flowered; peduncle $1.5-3.0 \mathrm{~cm}$, densely puberulent; bracts 3 , free, narrowly lanceolate, lateral ones ca. $20 \times 2-2.5 \mathrm{~mm}$, the central one ca. $5 \times 0.8-1 \mathrm{~mm}$, puberulent, margin entire, apex acute. Pedicel $0.5-1.0 \mathrm{~cm}$, densely puberulent. Calyx 5-sect from base; segments equal, lanceolate-ovate, ca. $15 \times 6 \mathrm{~mm}$, puberulent, margin entire, apex acute. Corolla purple, 4-6 cm, outside puberulent, inside glabrous; tube tubular, $2.5-4.8 \mathrm{~cm}$ long, base ca. 3-5 $\mathrm{mm}$ in diameter, top $12-16 \mathrm{~mm}$ in diameter; limb distinctly 2-lipped, adaxial lip 2-parted to the base, lobes ovate, ca. $10 \times 8 \mathrm{~mm}, 3$-lobed over the 
179 180 181 182 183 184

middle, lateral ones ovate, central one oblong, obtuse to truncate at apex, $12-15 \times 8-10 \mathrm{~mm}$.

Stamens 2, adnate to ca. $2 \mathrm{~cm}$ above the corolla tube base, filaments ca. $1 \mathrm{~cm}$ long, geniculate near the base, glabrous; anthers fused by their entire adaxial surfaces, elliptic, ca. $2.5 \mathrm{~mm}$ long, glabrous; staminodes 2, linear, 6-7 mm, glabrous. Pistil ca. $3 \mathrm{~cm}$, densely puberulent with both glandular and eglandular hairs; ovary ca. $2.0 \mathrm{~cm}$, glandular-puberulent. Stigma ligulate, lobes linear, $2-2.5 \mathrm{~mm}$ long. Capsule $2.5-3.0 \mathrm{~cm}$ long.

Distribution, Habitat and Ecology. Primulina hiemalis is locally abundant, narrowly endemic and only known from the type locality, i.e. Chuanyan village, Baishou Town, Yongfu county, Guangxi province. It grows on moist, shady cliffs at the entrance of a limestone cave, at an elevation of $530 \mathrm{~m}$ a.s.l. The average temperature is $18.8^{\circ} \mathrm{C}$, the average annual precipitation has been calculated at ca. 2,000 $\mathrm{mm}$. The forest where $P$. hiemalis occurs is subtropical evergreen broad-leaf forest. Flowering from November to January, fruiting in April.

Etymology. The specific epithet is derived from the species' winter flowering time. The Latin word "hiemalis" is an adjective, meaning "to belong to winter," and hints at the flowering time of the new taxon (November to January).

\section{DISCUSSION}

In contrast to its high species diversity, the morphological variation of Primulina is relatively limited compared to other genera (Möller et al. 2016). The corolla morphology, especially, is relatively uniform, and most species possess straightly infundibuliform corollas, with only the salverform (e.g. Primulina tabacum), campanulate (e.g. P. dichroantha, P. mollifolia, P. 
hezhouensis, and P. renifolia), and $P$. curvituba having a strongly curved tube shape. In addition,

Primulina displays a wide range of diversity of involucral bracts. The two opposite bracts are

brightly white when flowering and serve the function of attracting pollinators as in Primulina

eburnea, P. lutea, P. xiziae, P. lungzhouensis, P. lunglinensis, P. beiliuensis var. beiliuensis, $P$.

beiliuensis var. fimbribracteata and the new species, $P$. davidioides. The development of cymes

in these species shows that the two lateral paraclades of the pair-flowered cyme are reduced, so

all flowers are clustered together. While flowers of these species always blossom for a short

207

duration (Hong 2016), the large white bracts and central flower cluster make the inflorescence

look superficially like a single flower, perhaps to increase attraction for pollinators.

\section{CONSERVATION ASPECTS}

These two new species belong to a group of stenochoric plants which only grow in limestone

areas. Currently there is insufficient information concerning the distribution and population

status of these new species. Obviously, further field study is needed in northwestern Guangxi as

their geographic range may well be more extensive than presently known. Considering that not

enough is known about their populations, it is proposed that their conservation statuses should

currently be classed as data deficient (DD) (IUCN, 2016).

\section{CONCLUSIONS}

During our continuous floristic surveys of limestone karsts in recent years, two unknown species 
221 herbarium specimens, Primulina davidioides and $P$. hiemalis are recognized as two species new

222 to science based on results of detailed examination of morphological anatomical features.

223 Current information for these species is only known from very few collections, they appears to

224 be narrowly endemic and locally abundant based on our careful field investigations in the past

225 eight years.

226

227 ACKNOWLEDGEMENTS

228 The authors express our appreciation to the corresponding curators of the botanical collections 229 for facilitating our access to examined specimens. We thank Long-Fei Fu and Jia Dong for help 230 cultivation works and preparing comparative materials, to Zheng-Long Li, Fu-Zhuan Pan, Shu Li and Zi-Bing Xin for help conducting fieldwork and with logistics, and to Elizabeth Mchone from Drexel University for reviewing the English grammar and style. Thanks are also due to Xiao-

Ming Xu and Wen Ma for the beautiful hand-drawings. We also grateful to Michael Möller, and two anonymous reviewers for the valuable comments, that improved the manuscript.

\section{REFERENCES} Molecular Ecology Resources 15: 619-632. DOI 10.1111/1755-0998.12333

Ai B, Gao Y, Zhang X, Tao J, Kang M, Huang H. 2015. Comparative transcriptome resources of eleven Primulina species, a group of 'stone plants' from a biodiversity hot spot.

Clements R, Sodhi NS, Schilthuizen M, Ng PKL. 2006. Limestone karsts of Southeast Asia: imperiled arks of biodiversity. Bioscience 56:733-742. 
242 Gao Y, Ai B, Kong H, Kang M, Huang H. 2015. Geographical pattern of isolation and diversification in karst habitat islands: a case study in the Primulina eburnea complex. Journal of Biogeography, 42: 2131-2144.

Hong X. 2016. Research on conservation ecology of Primulina rare plants (in Chinese). Anhui Normal University PhD dissertation.

Hou MF, López-Pujol J, Qin HN, Wang LS, Liu Y. 2010. Distribution pattern and conservation priorities for vascular plants in Southern China: Guangxi Province as a case study. Botanical Studies 51:377-386.

IUCN 2016. Guidelines for using the IUCN Red List categories and criteria. Version 12. Prepared by the Standards and Petitions Subcommittee. http://jr.iucnredlist.org/documents/

Li ZY, Wang YZ. 2004. Plants of Gesneriaceae in China. Zhengzhou: Henan Science and Technology Publishing House.

Möller M, Wei YG, Wen F, Clark JL, Anton W. 2016. You win some you lose some: updated generic delineations and classification of Gesneriaceae implications for the family in China. Guihaia 36: 44-60

Möller M, Forrest A, Wei YG, Weber A. 2011. A molecular phylogenetic assessment of the advanced Asiatic and Malesian Didymocarpoid Gesneriaceae with focus on nonmonophyletic and monotypic genera. Plant Systematics and Evolution 292: 223- 248. DOI 10.1007/s00606-010-0413-z

Myers N, Mittermeier RA, Mittermeier CG, da Fonseca GAB, Kent J. 2000. Biodiversity 
hotspots for conservation priorities. Nature 403:853-858. DOI 10.1038/35002501.

264

265

266

267

268

269

270

271

272

273

274

275

276

277

278

279

280

281

282

283

Thiers B. 2017. Index Herbariorum: a global directory of public herbaria and associated staff. New York Botanical Garden’s Virtual Herbarium. http:// sweetgum.nybg.org/science/ih/. Accessed 10 Oct 2017

Wang S, Xie Y. 2004. China Species Red List. Higher Education Press, Beijing.

Wang WT, Pan KY, Li ZY. 1990. Gesneriaceae. Pp. 190-203 in Flora Reipublicae Popularis Sinicae vol. 69, ed. Wang WT. Beijing: Science Press.

Wang WT, Pan KY, Li ZY, Weitzman AL, Skog LE. 1998. Gesneriaceae. Pp. 268-272 in Flora of China vol. 18, eds Wu ZY, Raven PH. Beijing: Science Press, and St. Louis: Missouri Botanic Garden.

Wang YZ, Mao RB, Liu Y, Li JM, Dong Y, Li ZY, Smith JF. 2011. Phylogenetic reconstruction of Chirita and allies (Gesneriaceae) with taxonomic treatments. Journal of Systematics and Evolution 49: 50-64. DOI 10.1111/j.1759-6831.2010.00113.x

Wei YG, Wen F, Möller M, Monro A, Zhang Q, Gao Q, Mou HF, Zhong SH, Cui C. 2010. Gesneriaceae of South China. Guangxi Sciences and Technology Publishing House.

Wen F. 2008. Studies on investigation and introduction of wild ornamental resources of Gesneriaceae in Guangxi (in Chinese). Beijing Forestry University PhD dissertation.

Yang LH, Chen J, Wen F, Kang M. 2018. Primulina malipoensis (Gesneriaceae), a new species from Sino-Vietnamese border area. PhytoKeys 94: 107-116.

Ying JS, Zhang YL. 1994. The endemic genera of seed plants of China. Beijing: Science Press.

Zhang XL, Yang LH, Kang M. 2017. Post-pollination reproductive isolation of sympatric 


\section{Table $\mathbf{1}$ (on next page)}

Diagnostic character differences between Primulina davidioides sp. nov. and its close relatives $P$. lunglinensis. 
1 Table 1. Diagnostic character differences between Primulina davidioides sp. nov. and its close relatives $P$.

2 lunglinensis.

\begin{tabular}{|c|c|c|}
\hline Characters & P. davidioides & P. lunglinensis \\
\hline Indumentum of peduncles & puberulent & glandular puberulent \\
\hline Bracts & $\begin{array}{l}\text { cordate to suborbicular, base } \\
\text { subtruncate, } 4-6 \times 4-5 \mathrm{~cm}\end{array}$ & $\begin{array}{l}\text { elliptic to broadly ovate, base } \\
\text { attenuate, } 0.6-3.8 \times 0.4-2.7 \\
\mathrm{~cm}\end{array}$ \\
\hline Indumentum of Pedicel & glandular and eglandular pubescent & glandular puberulent \\
\hline Corolla size & ca. $6 \mathrm{~cm}$ long & $3-3.8 \mathrm{~cm}$ long \\
\hline Number of staminodes & 3 & 2 \\
\hline Pistil & $\begin{array}{l}\text { ca. } 3.7 \mathrm{~cm} \text { long, glandular and } \\
\text { eglandular pubescent }\end{array}$ & ca. $2.7 \mathrm{~cm}$ long, puberulent \\
\hline Shape of Stigma & narrowly obtrapeziform & cuneate \\
\hline
\end{tabular}

3

4 


\section{Table 2 (on next page)}

Diagnostic character differences between Primulina hiemalis sp. nov. and its close relatives $P$. luzhaiensis. 
1 Table 2. Diagnostic character differences between Primulina hiemalis sp. nov. and its close relatives $P$.

2 luzhaiensis.

\begin{tabular}{|c|c|c|}
\hline Characters & P. hiemalis & P. luzhaiensis \\
\hline Indumentum of of leaf blade & puberulent on both surfaces & villous and pubescent adaxilly \\
\hline Indumentum of peduncle & densely puberulent & densely villous \\
\hline Bracts & $\begin{array}{l}3 \text {, lateral ones ca. } 2 \mathrm{~cm} \text { long, } \\
\text { the central one ca. } 0.5 \mathrm{~cm} \text { long }\end{array}$ & $2,0.2-0.8 \mathrm{~mm}$ long \\
\hline Calyx size & ca. $1.5 \mathrm{~cm}$ long & $0.5-1 \mathrm{~cm}$ long \\
\hline The location of stamens & $\begin{array}{l}\text { adnate to ca. } 2 \mathrm{~cm} \text { above the } \\
\text { corolla tube base }\end{array}$ & $\begin{array}{l}\text { adnate to } 1.4-1.7 \mathrm{~mm} \text { above the } \\
\text { corolla tube base }\end{array}$ \\
\hline Number of staminodes & 2 & 3 \\
\hline Shape of stigma & ligulate, apex 2-lobed to middle & obtrapeziform, apex retuse \\
\hline
\end{tabular}

3

4 


\section{Figure 1}

Illustration of Primulina davidioides sp. nov.

(A) habit in flowering period; (B) dissection of a flower showing stamens and staminodes; (C) anthers, showing beard; (D) pistil; (E) stigma; (F) ovary and calyx; (G) calyx (Image credit: Xiao-Ming Xu, drawn from the holotype). 


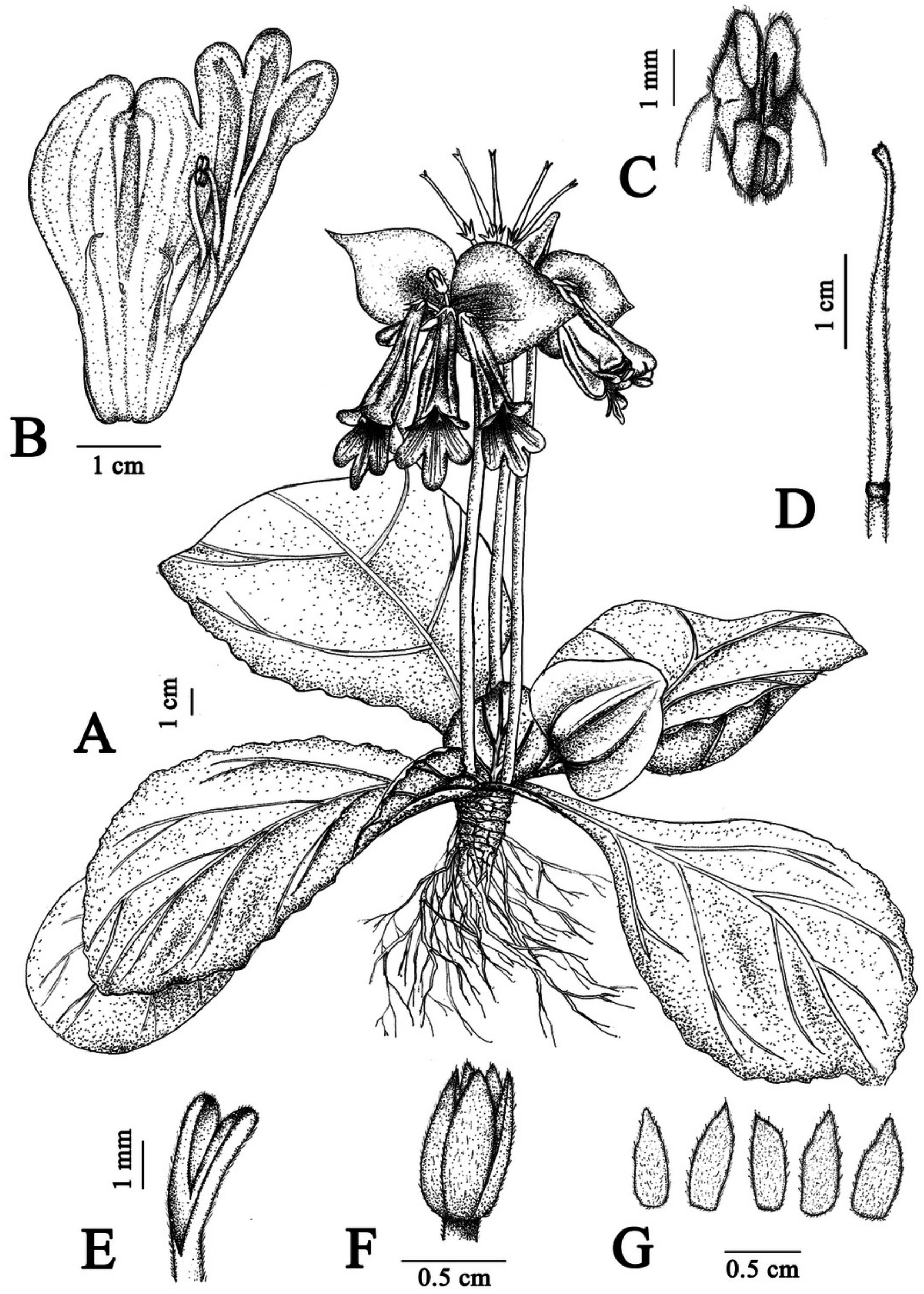

PeerJ reviewing PDF | (2018:02:23971:2:0:NEW 15 May 2018) 


\section{Figure 2}

Photographs of Primulina davidioides sp. nov.

(A) habitat; (B) population; (C) the flower bud; (D) flowering plant with cymes; $\mathrm{E}-\mathrm{H}$ : cymes:

(E) showing adaxial bracts; (F) showing abaxial bracts; (G) frontal view of cymes; (H) top view of cymes); (I) lateral view of corolla; (J) young fruit; (K) top view of corolla; (L) upward view of corolla; (N) opened corolla, pistils without corolla and calyx lobes; (O) dissection of a flower showing staminodes; $\mathrm{P}-\mathrm{Q}$ : stamens (P) the reverse side, showing beard; $(\mathrm{Q})$ the frontal side, showing the anthers; (R) capsules (Photo credit: Fang Wen and Xin Hong). 

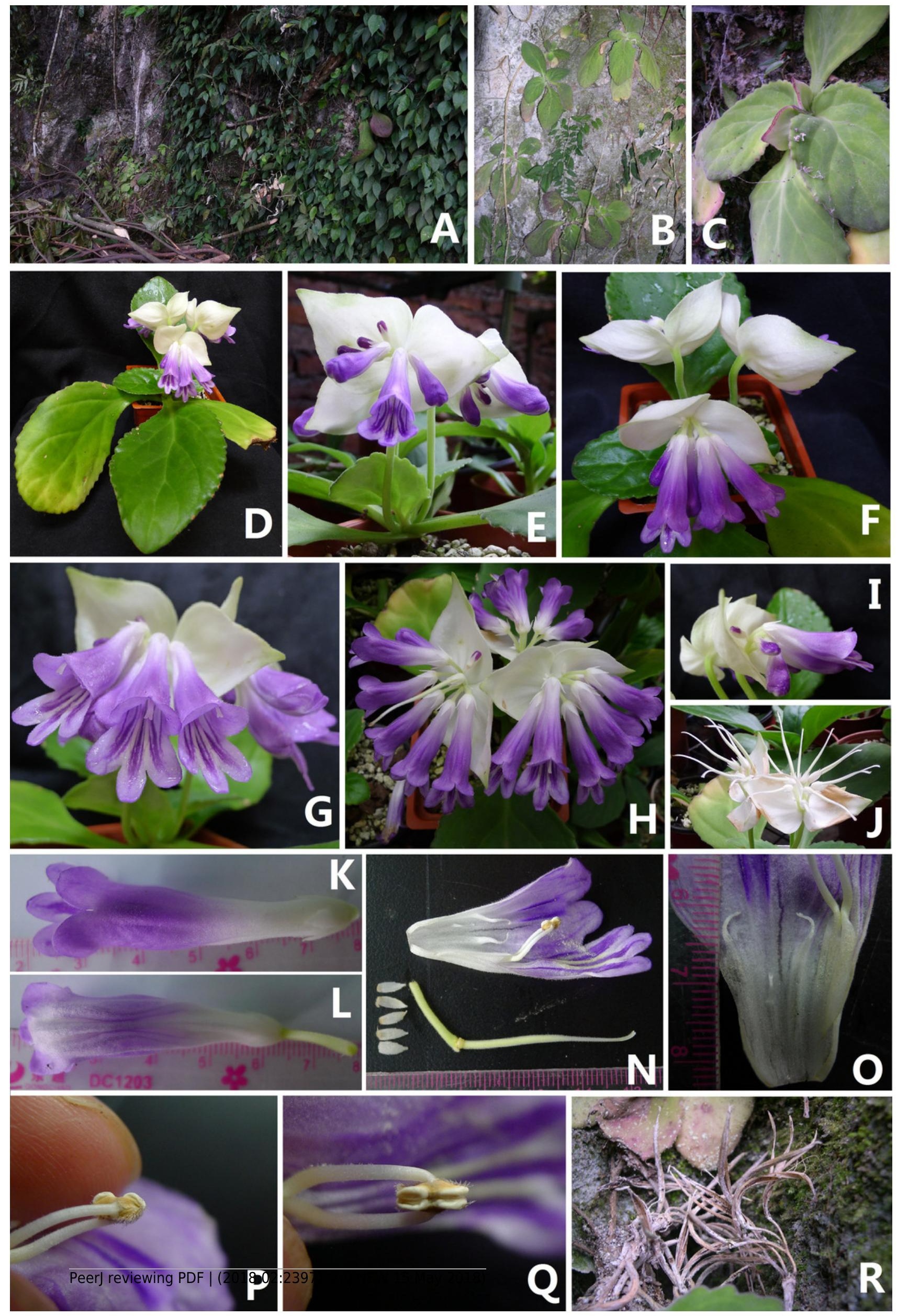


\section{Figure 3}

Illustration of Primulina hiemalis sp. nov.

(A) habit in flowering period; (B) dissection of a flower showing stamens and staminodes; (C) calyx and pistil; (D) calyx, showing puberulence (Wen Ma, drawn from the holotype). 

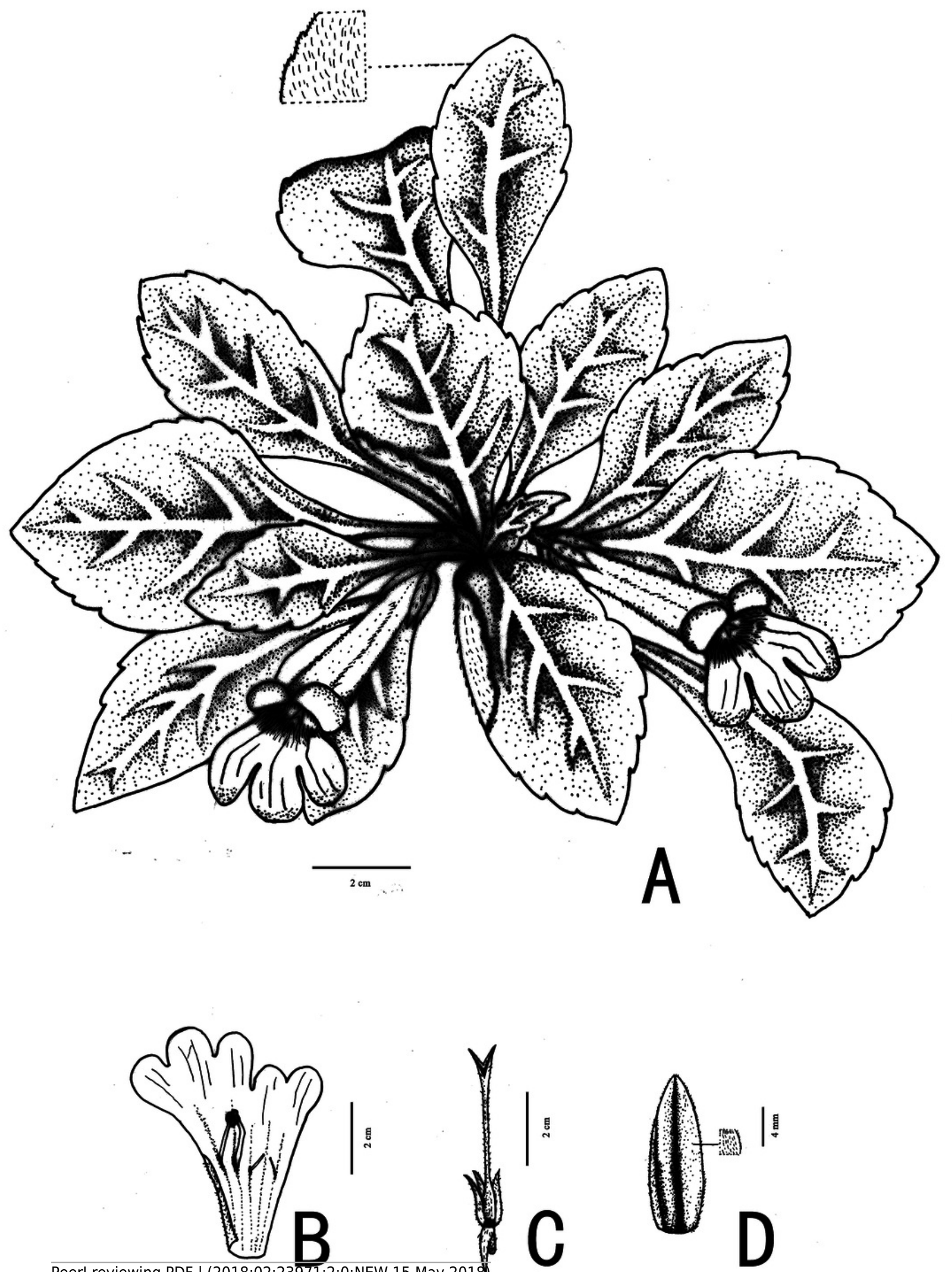


\section{Figure 4}

Photographs of Primulina hiemalis sp. nov.

(A) habitat; (B) plant; C-F: corolla: (C) frontal view; (D) right side view; (E) top view; (F) left side view; (G) calyx; (H) pistils with calyx lobes, showing the stigma; (I) opened corolla (Photo credit: Fang Wen). 

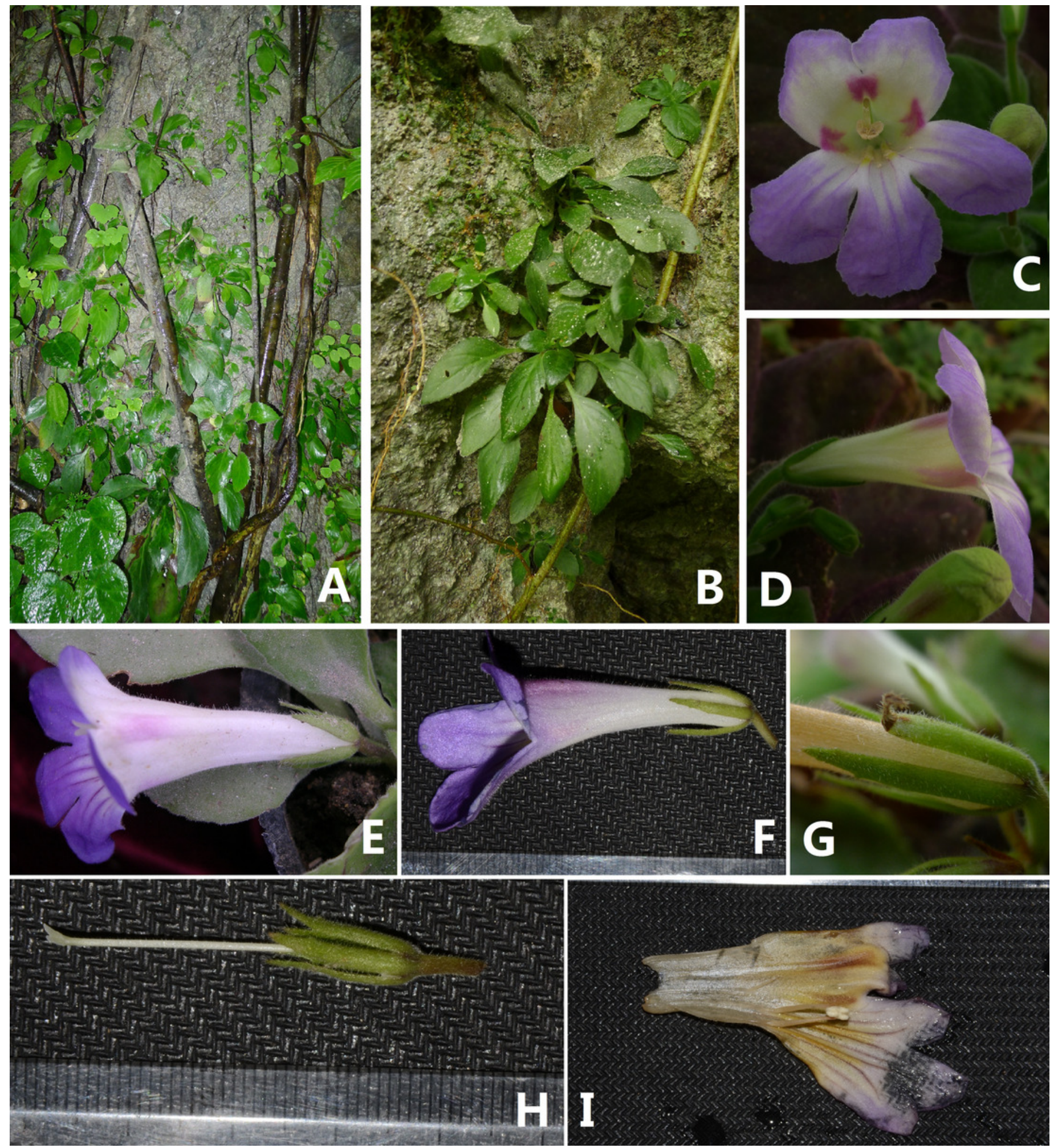